\title{
A CULTURA SURDA E OS INTÉRPRETES DE LÍNGUA DE SINAIS
} (ILS)

\author{
Gladis Perlin
}
“A pior alienação não consiste em ser despossuído pelo outro, mas em ser despossuído do outro".
BAUDRILLARD

\section{RESUMO}

Enfatizando algumas posições e enunciações sobre a cultura surda o artigo pretende discorrer sobre a identidade e o território do interprete de língua de sinais/português. Aborda certas situações, porém não tanto a globalidade da questão. Salienta que o interprete não se realiza no simples ato da tradução, mas que envolve uma gama dimensional de significantes e significados que denunciam a complexidade de seu papel, as dimensões e a profundidade de sua atuação. Os intérpretes são para a tradução da cultura, da língua, da história, dos movimentos, das políticas da identidade e da subjetividade surda, e apresentam suas próprias particularidades, identidade e orbitalidade.

\section{PALAVRAS-CHAVE}

Cultura; Intérprete de língua de sinais/português; Surdos; Identidade.

\section{DEAF CULTURE AND THE SIGN LANGUAGE INTERPRETERS}

\section{ABSTRACT}

By emphasizing some positions and enunciations on deaf culture, this paper aims to discuss the identity and the territory of the Sign Language/Portuguese interpreter. Certain situations are approached; however, our focus is not on how global the issue is. We point out the fact that not only does the interpreter work on the translation act itself, but on the myriad signifiers and signifieds that reveal the complexity of his or her role, the dimensions and the depth of his or her actions. The interpreters work on the translation of culture, language, history, movements, and politics of deaf identity and subjectivity, and they present their own particularities, identities and orbital characteristics.

\section{KEY WORDS}

Culture; Sign language/portuguese interpreter; Deaf; Identity. 


\section{ARTIGO \\ Processos Tradutórios, Línguas de Sinais e Educação \\ Grupo de Estudos e Subjetividade}

\section{INTRODUÇÃO}

No contexto do pós-moderno, a presença do particular, do especificamente diferente, do exótico, ganha espaços de produção. Somos constantemente convidados a excluir a sedução proveniente do exterior. Nota-se um movimento particular ocasionando hibridismos, desaparecimentos, perdas, mudanças, surgimentos. São estes os tempos de desorientação cultural e/ou de afirmação de novas identidades?(SKLIAR, 2003, p. 48)

Muitas e produtivas abordagens são feitas hoje com os espaços da produção cultural. Somos artífices dessas trajetórias, identidades e territórios que envolvem os sujeitos da cultura na pós-modernidade. Sentimos necessidade permanente de horizonte onde desenvolvemos a experiência humana. Este é o horizonte da cultura. Chegamos ao exótico. O negro, o índio, o surdo desvelando-se com algo particular, como diz Hall (2003, p.83), “todos nos localizamos em vocabulários culturais e sem eles não conseguimos produzir enunciações enquanto sujeitos culturais”. Nós, surdos, nesse contexto da modernidade tardia, estamos ${ }^{1}$ construindo os espaços de nossa cultura estabelecendo vínculos com aqueles que compartilham nosso mundo e são diferentes de nós.

Muitos trabalhos já foram realizados sobre a complexidade e especificidades da cultura surda: Padden e Humphries (1988); Wrigley (1996); Skliar (1998); Quadros (1999); Miranda (2002); Lopes (1998); Thoma (1998); Lunardi (1998); Lulkin (1998);. Stumpf (2003); Rangel(2003); Perlin (1998).

As produções da cultura surda se ampliaram hoje. Algumas produções culturais dos surdos como a identidade, a diferença, a língua de sinais, a compreensão das posições do sujeito (surdo e ouvinte), a poesia e a escrita da língua de sinais se adentram como questões necessárias à tradução da alteridade do sujeito surdo. Conseqüentemente, as posições contrárias de representação ${ }^{2}$ foram perdendo terreno e, em alguns espaços, formas radicais assumem gerando impulsos que permitem aos sujeitos indícios de direção.

Tenho observado que entre as diferentes culturas algumas preferem discutir sob o ângulo do multiculturalismo, sob a condição da continuidade da subalternidade. Em grande parte, os surdos latino-americanos não se deixam levar por isto. Nós, surdos, entendemos

\footnotetext{
${ }^{1}$ Subjetiva e simplesmente sou surda e, como surda, me insiro como sujeito do processo cultural dos surdos. ${ }^{2}$ Os estereótipos referentes aos surdos perdem espaços e os novos achados com a teoria dos estudos culturais permitem entender a dimensão cultural e lingüística dos surdos.
} 
nossa cultura em sua dimensão constitutiva e, assim como os índios, pretendemos lutar pela defesa da mesma, bem como de nossa língua, nossa diferença, nossa pedagogia.

Discutirei, neste ensaio, algumas das representações da cultura surda, posições e enunciações. Igualmente, pretendo tecer considerações sobre a trajetória da identidade e o território do interprete de língua de sinais - ILS. Sobre estes paradigmas podemos considerar certas situações, porém, não daríamos conta da globalidade da questão. Se reduzíssemos o ILS ao ato de tradução, teríamos que encobrir uma gama dimensional de significantes e significados. Quanto mais se reflete sobre a presença do ILS, mais se compreende a complexidade de seu papel, as dimensões e a profundidade de sua atuação. Mais se percebe que os ILS são também interpretes da cultura, da língua, da história, dos movimentos, das políticas da identidade e da subjetividade surda, e apresentam suas particularidades, sua identidade, sua orbitalidade ${ }^{3}$.

Vale a afirmação de Baudrillard (2000, p. 109) de que sempre haverá uma alteridade total com seu secreto impenetrável ${ }^{4}$. Muito se tem escrito sobre o intérprete, contudo ainda há muito a dizer no campo da aproximação cultural. Nesse sentido, a trajetória, a identidade e a territorialidade cultural são as três perspectivas sob as quais localizaremos o intérprete.

No terreno da comunicação em que se insere o ILS se desenrola uma multifacetada problemática da interpretação. Neste contexto, o conhecimento da diferença cultural $^{5}$ influi sobre a qualidade de sua interpretação muito mais que a simples amizade ou a intimidade.

\section{A CULTURA SURDA SOB O SIGNO DA DIFERENÇA}

A cultura surda traz em si elementos importantes que a identificam, a constituem e a colocam no rol das diferentes culturas que perfazem o panorama das posições da modernidade $\operatorname{tardia}^{6}$. Os espaços das culturas são regidos por poderosas tramas de poder. Cada cultura é em si mesma autoridade. Uma cultura difere da outra pelo enunciado, pelas tramas de poder e pelas narrativas que a constituem. Estas 3 abordagens podem auxiliar na descrição e reinscrição cultural.

\footnotetext{
${ }^{3}$ Termo utilizado por Baudrillard (2000 p. 57) no sentido de trajetória.

${ }^{4}$ Tradução minha.

${ }^{5}$ A diferença cultural está significando o processo relativamente associado a políticas de significação e produções culturais especificas.

${ }^{6}$ Tempos do pós-modernismo em que as culturas se fixam na celebração da diferença, e deslegitimam as fontes tradicionais que as mantêm sob significados universalizantes. 
O problema das abordagens acontece quando os discursos nas enunciações para as representações culturais se revestem do aparato popular ${ }^{7}$. Bhabha (1998, p. 95) salienta um tipo de enunciação: o ato da enunciação colonial, da contestação cultural. Um ato que mantém diversas culturas na insuficiência ou as nomeia como ameaça a ordem na sociedade, um ato que as incrimina como desconstrução ${ }^{8}$ da ordem moral.

Este aspecto presente enfatiza o culturalismo que, de acordo com Thompson (2005, p. 23), sempre atrela os olhares e as formas de representação do mundo - e da alteridade - a uma ideologia que mantém na subalternidade modos outros de ler, inventar, escrever o mundo e as relações sociais. Se assim considerarmos, pode-se dizer que as formas de representar, pesquisar e escutar o surdo estão fortemente marcadas por uma concepção falante e ouvinte de normalidade. Dito de outro modo, são atravessadas por traços simbólicos que geram o efeito de naturalização da superioridade (normal) das culturas ouvintes sobre as surdas (vistas como subalternas ou deficitárias).

Para uma elucidação sobre a forma do ILS atuar na defesa da diferença cultural significativa, vamos a um fato ocorrido nos campos da educação, no qual a sua presença se faz mais marcante, devido ao incentivo governamental sobre sua presença em educação. Quadros (2004, p. 86) salienta: “Aqui se percebe sutilmente que as representações da cultura hegemônica, ou seja, da cultura ouvinte, estão nas entranhas das propostas de inclusão. A cultura hegemônica tende sempre a produzir populações politizadas de acordo com sua representação”. Com este discurso, Quadros (2004) remete para a realidade onde devia se inserir a cultura surda. Analisando as palavras de Quadros (2004), que também é ILS, nota-se uma resposta política contra a identidade arrogante, ou a suposta superioridade da cultura hegemônica. Quadros (2004) também refere a diferença cultural e a enfatiza entre cultura hegemônica e cultura dos surdos.

Quadros (2004) propõe a diferença. O que vem a ser esta diferença? A diferença pela diferença equivale a dizer: as identidades no interior de uma cultura são diferentes entre si assim como as culturas diferem entre si. A différance ${ }^{9}$, como definida por Derrida (GABILONDO, 2001), é perpassada pela alteridade cultural. Dessa forma, o sujeito surdo

\footnotetext{
${ }^{7}$ Representações sobre certas culturas certas culturas como subalternas, não levando em conta sua diferença e especificidade.

${ }^{8}$ Desconstrução: o momento em que construímos uma diferença, conhecendo a estrutura a respeitamos, mas a desconstruimos e construímos do e ao nosso jeito surdo.

${ }_{9}^{9}$ Diférance: Derrida cunhou o termo no sentido de significar a diferença pela diferença. Assinala que o processo de significação depende da diferença entre as diferenças. 
serve-se em sua subjetividade da cultura surda, serve-se da diferença devido que aquilo que aflui na experiência cultural nunca é de forma igual e vai constituir sua subjetividade.

\section{ASPECTOS DA IDENTIDADE CULTURAL DOS SURDOS}

A minha intenção de trazer para aqui alguns sistemas simbólicos do interior da cultura surda não é no sentido de persuadir, nem de trazer a totalidade cultural, mas no sentido de repaginar alguns pontos essenciais. Quando se fala de cultura surda acontece na maioria das vezes que se fica perdido entre o que é e o que não é cultura surda. A seguir destaco alguns elementos culturais mais conhecidos que vale a pena retomar:

Identidade surda: constitui-se no interior da cultura surda. Está em situação de dependência, de necessidade do outro surdo (PERLIN, 1998, p. 53). As identidades surdas são multifacetadas, fragmentadas, em constante mudança; jamais se encontra uma identidade mestra, um foco. Os surdos passam a serem surdos através da experiência visual, de adquirir certo jeito de ser surdo.

Diferença: Por diferença entendemos o ser surdo com sua alteridade. Por exemplo, se perguntarmos: Porque os surdos querem escolas de Surdos? A resposta identifica a caminhada para a diferença: “para tornarem-se sujeitos de sua história”, saírem da exclusão, construírem sua identidade em presença do outro surdo, para terem direito à presença cultural própria.

Língua de Sinais:Uma das maiores produções culturais dos surdos refere língua de sinais. Os estudos mais recentes (QUADROS; KARNOPP, 2004) sobre ela têm atestado a incomensurabilidade da nossa riqueza lingüística. Uma das preocupações entre os surdos nas constituições das relações interculturais se trata da língua de sinais. A agonia dos signos da língua de sinais é o sintoma mais presente detectado nas relações interculturais. Sinais que perderam sua significância visual, sinais que já não agrupam o fluxo significativo dos signos visuais e que se deterioram.

Poder: Os termos: eles ouvintes e nós os surdos e cultura surda e cultura ouvinte são formas de nos identificarmos nas posições do sujeito fortemente marcadas pelas relações de poder como diz Silva (2000, p.82). Não se trata de categorias nem de divisões binárias como 
querem, mas de posições de identidade e de diferença. Divisões binárias sempre implicam em dominado e dominador e na luta entre ambos como pesquisou Derrida (SILVA, 2000, p.83).

\section{A IDENTIDADE DO ILS EM CONSTRUÇÃO.}

Uma das questões que assumem complexidade no momento de se aproximar os ILS dos Estudos Culturais é teorizar sobre a identidade do ILS. Para Paul Gilroy (1998, p. 64) o substantivo “identidade” aparece ligado ao adjetivo “cultural”. Alguns ILS já percebem que a constituição da identidade tem elementos culturais significativos na alteridade como ILS. Notam também que a articulação com a cultura surda se constitui em algo específico. Ao mesmo tempo em que identifica o ILS, ela não é a cultura do ILS, portanto empurra em diferentes direções, diferentes identidades. Daí porque as reações dos sujeitos diante da cultura surda são as mais variadas constituindo, portanto, identificações diferentes em diferentes momentos.

A identidade igualmente se elucida num contexto distinguindo-se e tornando-a presente. Se levarmos em conta a afirmação de Hall (2003, p. 85) que: “cada identidade é radicalmente insuficiente em termos de seus outros”; estaremos posicionados a entendermos que complexas cadeias conceituais e organizacionais passam a serem reconhecidas como parte da identidade do ILS. Essas cadeias são perpassadas pela interatividade cultural. Retornando a Gilroy (1998, p. 67) tem-se que a identidade é “ineludivelmente política” de forma especial em seus modelos de identificação que aceleram a sua contração. Enfatizando, a identidade do ILS é alimentada, criada, reforçada e por vezes subvertida pela cultura surda.

Não se pode dizer que as identidades são puras, prontas, homogêneas, não se pode dizer que uma identidade pertence apenas a uma cultura. Importa dizer da complexidade das identidades. Importa dizer que não existe uma identidade sem situá-la em sua territorialidade cultural, no sentido, um contexto. Isso pode significar que esta orbitalidade que perpassa a identidade, ao mesmo tempo em que constitui o ILS, põe uma falta constitutiva em relação à 
cultura surda $^{10}$. Como observa Aléxis López (2001, p.187): respostas como estas me fazem pensar nas diferentes relações que se estabelecem entre os diversos grupos humanos, nos processos de constituição das identidades e nas dinâmicas de poder que implica tudo isto. O ILS se constitui enquanto identidade no interior de diferentes culturas nas quais faz intermediação.

Friedman (1994, p. 330) discorre sobre a negociação das identidades no ato do consumo da cultura. Inclusive para ele fica claro que as diferenças de estratégias de identidades sempre são locais. Daí decorre que o mecanismo de identificação do ILS envolve relações entre sujeitos e entre culturas. O significado/identidade ILS está constituído por uma poderosa trama de implicações culturais, políticas e de relações de poder. É um fato que esta constituição da identidade permaneça pluralística e os elementos retenham sua différance. No entanto também é um fato que algumas identidades se inscrevam como argumentos políticos na ascendência cultural de forma mais poderosa.

\section{OS PROCESSOS DE NARRATIVAS (INTERPRETAÇÕES) DOS ILS.}

O ILS trabalha no espaço intercultural, é para o processo de "transvaloração cultural" (BHABHA,1998) que esta profissão surgiu. O ILS é para intermediar a cultura surda e a outra cultura pautada na audição e na fala. Não se deve negar aqui que as narrativas culturais assumem o momento da tradução/interpretação. Entendo aqui por narrativa o tipo de discurso que o ILS assume no momento que traduz os diálogos de uma cultura a outra. A fidelidade da tradução acontece à medida da compreensão do outro, acontece à medida da compreensão cultural. O poder se insere no discurso da narrativa. Carbonelli I Cortés (1999, p.40) chama a atenção para o fato de que algo se passa no diálogo entre culturas. A meu ver, narrativas culturais são as formas de uma cultura traduzir à outra sua constituição, seus valores, as realidades escolhidas e seu modo de representação cultural.

Souza (2000, p. 92) diz que "no caso dos surdos faz-se necessário franquear-lhes a palavra, quer dizer que, antes de escreverem em nosso idioma deveriam poder se narrarem em sinais, e suas narrativas precisariam ser acolhidas por uma escuta nossa também em sinais”.

\footnotetext{
${ }^{10}$ Citar cultura surda e cultura ouvinte não constitui aqui volta a divisão binária que transforma surdos em radicais, mas em estratégias de posições do sujeito. Posições nas quais o sujeito se movimenta para constituir sua identidade, sua diferença.
} 
Para a autora esta escuta do surdo merece atenção em língua de sinais, e para nós - surdos - é sabido que ela é mais que língua de sinais.

Há diferentes modos de realizar a tradução cultural - da cultura surda - que pode ser feita sob formas múltiplas. Citaríamos aqui os extremos. Sob uma perspectiva, somos tomados como se fôssemos retardados, vivêssemos fora das fronteiras da normalidade, no perigoso distanciamento da língua nacional, no gueto, no âmbito de necessitados de cultura. Sob outra, a tradução funciona como uma perspectiva da diferença cultural. Sob a perspectiva da diferença cultural adapto as palavras de Carbonelli I Cortés (1999, p. 48) tentando esclarecer o processo: “(...) mais que aos problemas lingüísticos de fidelidade ao texto de origem”. A tradução na teoria cultural contemporânea, "trata das relações entre as condições de produção de conhecimento em uma cultura dada e como um saber procedente de um contexto cultural diferente se relocaliza e se reinterpreta segundo as condições nas quais tem lugar todo conhecimento".

Fica evidente que uma reinscrição cultural do surdo é construída e repassada de acordo com o conhecimento cultural do ILS. O conhecimento cultural se dá por uma legitimação, por uma percepção da diferença.

Isto implica na possibilidade das posições de poder serem assumidas de forma a que a cultura surda se livre das longas dominações e representações equivocadas dos ouvintes. Essa diferença requer que os processos tradutórios, em si, contenham significâncias que incidam a produção de sentido cultural enfatizados no próprio ato de tradução/interpretação. Ela requer, ainda, ser permeada por políticas da diferença, certamente em perspectivas que incidem de forma fortalecedora da cultura, que seguramente poderão causar mal estar a cultura dominante. É preciso dizer que não se trata de uma deformação da cultura dominante, mas, um claro direito à diferença, à construção cultural de forma diferenciada.

\section{QUESTÕES DE APROXIMAÇÃO DAS FRONTEIRAS CULTURAIS.}

Nas narrativas dos ILS entra um conjunto de situações em que aparecem incompletudes. As identidades dos ILS não preenchem muitas das exigências culturais dos surdos. Questões de pertença e de vínculo são freqüentemente contestadas pelos surdos. Uma situação difícil é a de definir o ILS e a situação cultural. Santos (2005, p.3) narrando sobre sua posição como ILS, nota: 


\section{ARTIGO \\ Processos Tradutórios, Línguas de Sinais e Educação Grupo de Estudos e Subjetividade}

Observo que houve um estranhamento cultural quando entrei no mundo dos surdos, vivendo a imersão em sua cultura. Talvez as palavras que poderiam resumir tal experiência seriam sentimento de ser estrangeirismo, de ser forasteiro.

No meio do povo surdo ${ }^{11}$, alguns ILS são mais aceitos que outros, reconhecidos como identidades mais compatível com a cultura surda. Isto significa que o intérprete emerge de certas relações políticas de discursos referentes à cultura surda. E na figura cúmplice do intérprete, aceita no povo surdo, existe a reinscrição cultural referencialmente política.

Daí que o trânsito do ILS nas fronteiras culturais exige que se esteja preparado para romper com uma série de artefatos coloniais como a enunciação da cultura surda vista ainda figura subalterna, ou como inexistente em algumas frações sociais. É obvio que o povo surdo guarda as tradições culturais. E a cultura surda também contém estratégias que regulam e controlam a vida dos surdos. Nota-se que, tal como as demais culturas, seu estilo é relevante.

Naturalmente, poderia limitar-me a dizer que a reordenação cultural pós-moderna ${ }^{12}$ seria suficiente para a identidade do intérprete. Mas, além disso, o ILS se constitui nas fronteiras da cultura surda. O ILS sempre fala de novo de voltar para casa ${ }^{13}$. E para o ILS a cultura surda se constitui apenas em um aspecto de sua cultura. No caso da colocação de Santos (2005): “Quem é o estrangeiro, quem é o outro?” O intérprete está identificado pela sua aproximação cultural com o sujeito surdo. A aproximação cultural produz os efeitosidentidade que são sempre cruciais, ora expondo uma alteridade interdita ${ }^{14}$, ora aproximando o hibridismo cultural. A produção cultural surda se hibridiza com o intérprete.

Essa produção em vista da diferença assegura a enunciação da representação cultural no processo de sua imersão política. Para lembrar, o fio cortante da tradução e da negociação cultural oscila entre a diversidade e a diferença. A atuação política do ILS acontece também no momento da tradução.

Na diferença a qualificação do intérprete assume sua importância no momento político. O momento político é atuante no momento das relações de reconhecimento, no momento do afastamento de posições de poder colonizador, de forma a que o intérprete se constitua no sujeito mediador entre culturas.

\footnotetext{
${ }^{11}$ Povo surdo: utilizamos o termo em vista de abranger plexo processo de organização dos surdos e sua cultura ser consistente.

${ }^{12}$ Neste sentido nos contentaríamos com múltiplas culturas, múltiplas identidades do intérprete.

${ }^{13} \mathrm{O}$ intérprete sempre de novo volta a ser ouvinte, tem necessidade de ouvir, de conviver com seus pares.

${ }^{14}$ Como dizer que o ILS é surdo? Ele apenas participa do momento visual do surdo. Atende um hibridismo.

(C) ETD - Educação Temática Digital, Campinas, v.7, n.2, p.136-147, jun. 2006 - ISSN: 1676-2592. 


\section{QUALIFICAÇÃO SÓCIO-CULTURAL DO INTÉRPRETE}

Compete-me, agora, a afirmar que o movimento da cultura surda também está dirigido para a formação do intérprete, para sua qualificação social e cultural. O momento da atuação do ILS é para as trocas culturais e sua profissão traz justamente toda uma estratégia de interpretação, de identificação, de bem-estar, simpatia pela cultura surda, e articulação cultural.

Estratégias para a qualificação dos ILS têm sido apresentadas pelos próprios ILS e por parte das duas culturas: surda e ouvinte. Cabe processar esta formação em diferentes níveis entre eles o epistemológico, o político e o estratégico. Em nível epistemológico poderíamos entender o modo de pensar a cultura, as mediações interculturais, por político os jogos de poder e os estratégicos que são as articulações em torno das especificidades da interpretação.

A formação que está para ser feita em nível de graduação na UFSC merece ser devidamente conduzida inclusive em sua articulação cultural. A importância do momento pede a organização dos intérpretes em torno de seus interesses profissionais e referência cultural.

\section{CONCLUSÃO REMANESCENTE}

Entre os surdos há aqueles que remetem o intérprete como mal necessário. O ILS atua na intermediação cultural, atua na fronteira cultural das culturas ouvintes e surdas. Temos de reconhecer a identidade do ILS não como um processo de manipulação, mas como uma identidade política no momento aproximação cultural. Ela influi em suas atuações consensuais de significações culturais.

A identidade ILS, vale dizer, não é somente cultural. Ela igualmente desencadeia uma ação política, ela se mantém graças a estratégias políticas culturais. Os são tradutores da cultura, da língua, da história, dos movimentos, das políticas da identidade e da subjetividade da cultura surda. Aos ILS que dizem que têm identidade surda, ou simplesmente que são surdos, que pertencem à cultura surda, ou que simplesmente negam nossa cultura e nossa diferença, respondemos que nós somos o surdos, e que devem construir e defender sua identidade em colaboração conjunta. 
Não há nada em nossa cultura surda que nos permita pensar em acabar com a presença do ILS. O movimento de nossa cultura está também dirigido para a formação do intérprete, para sua qualificação social e cultural. O mesmo deve ser por parte dos ILS e de outras culturas.

\section{REFERÊNCIAS:}

BAUDRILLARD, J.; GUILLAUME, M. La huella del otro. México: Taurus, 2000.

BHABHA, H. K. O local da cultura. Belo Horizonte: UFMG, 1998.

CARBONELLI I CORTÉS, O. Traducir al otro: Traducción, exotismo, poscolonialismo. Cuenca: Ediciones de la Universidad de Castilla - La Mancha, 1999.

FRIEDMAN J. Ser no mundo: globalizacão e localizacão. In. FEATHEROSTONE (Org.) Cultura global. Nacionalismo, globalização e modernidade. Petrópolis: Vozes, 1994.

GABILONDO, A.. La vuelta del Outro. Diferença, identidad, alteridad. Madrid: Editorial Trotta, 2001.

GILROY, P.. Los estudios culturales británicos y las trampas de la identidad. In CURRAN, J.; MORLEY, D.; e WALKERDINE, V. Estudios culturales y comunicación. Paidós, Buenos Aires,1998.

HALL, S. A questão multicultural. In: SOVIK, L. (Org.) Da diáspora identidades e mediações culturais. Belo Horizonte: Editora UFMG/UNESCO, 2003.

LACERDA, C. O interprete de íngua de sinais no contexto de uma sala de alunos ouvintes. In: LACERDA, C., GÓES, M. C. R. (Orgs.) Surdez - Processos educativos e subjetividade. S. Paulo: Lovise, ps. 51-84, 2000.

LÓPEZ, A. Ser ou não ser Triqui: Entre o narrativo e o político. In LARROSA, J. \& SKLIAR, C. Habitantes de Babel. Política e poética da diferença. Belo Horizonte: Editora Autêntica, 2001.

PADDEN, C. H. Deaf in America - voices from a culture. London: Harvard University Press, 1988.

PERLIN, G. Identidades Surdas. In: SKLIAR (Org.). A surdez: um olhar sobre as diferenças. Porto Alegre: Mediação, 1998.

QUADROS, R. Situando as diferenças implicadas na educação de surdos: inclusão/exclusão. Revista Ponto de Vista, UFSC, n. 5, 2004. 
SANTOS, S. A constituição da identidade de ILS que atuam no ensino superior. Proposta de qualificação de Mestrado. PPGE/UFSC, 2005.

SILVA T. T. da (Org.) Identidade e Diferença. A perspectiva dos Estudos Culturais. Petrópolis: Vozes, 2000.

SKLIAR, C. B. Pedagogia (improvável) da diferença: e se o outro não estivesse lá? Rio de Janeiro: DP\&A, 2003.

SOUZA, R. M. Práticas alfabetizadoras e subjetividade. In: In: LACERDA, C., GÓES, M. C. R. (Orgs.) Surdez - Processos educativos e subjetividade. S. Paulo: Lovise, 2000.

THOMPSON, K. Estudos Culturais e educação no mundo contemporâneo. In SILVEIRA, R. M.. (Org.) Cultura, poder e educação. Um debate sobre Estudos Culturais em Educação. Canoas: ULBRA, 2005.

WRIGLEY. O. The politics of deafness. Washingnton: Gallaudet University Press, 1996 